\title{
AS FACES DE DEUS: UM ESTUDO EXPLORATÓRIO COM CRIANÇAS E ADOLESCENTES ${ }^{1}$
}

\author{
Lorena Santos Ricardo ${ }^{2}$ \\ Antônio Carlos Ortega ${ }^{3}$ \\ Heloisa Moulin de Alencar ${ }^{4}$
}

Resumo: As representaçóes sobre Deus são elaboradas com o mesmo objetivo que o são todas as representaçóes sobre as quais versa o conhecimento social (organizar, explicar e significar o que ocorre em seu meio). Assim, objetivou-se investigar as representaçôes de crianças e adolescentes acerca de Deus, por meio de entrevistas baseadas no método clínico piagetiano, com sujeitos de 6, 10 e 14 anos. Foram elaborados critérios para análise das repostas, baseados no trabalho de Delval e Muriá Vila (2008), de forma a permitir identificar diferentes níveis de elaboração dessa representaçáo. Os resultados não apresentam diferenças relevantes entre as idades em relação ao nível da representação de Deus. Contudo, colaboram com as discussões acerca da construção de tais representações. Novas pesquisas se fazem necessárias com um número maior de participantes e uma amostra mais

1 Os autores agradecem à Fundação de Amparo à Pesquisa e Inovaçáo do Espírito Santo (FAPES) e à Coordenação de Aperfeiçoamento de Pessoal de Nível Superior (CAPES) pelo apoio financeiro.

2 Mestre em Psicologia. Doutoranda em Psicologia pela Universidade Federal do Espírito Santo. Contato: lorena.sricardo@gmail.com

3 Pós-doutor em Psicologia. Professor Colaborador do Programa de Pós-Graduaçáo em Psicologia da Universidade Federal do Espírito Santo. Contato: acortega@terra.com.br

4 Doutora em Psicologia Escolar e do Desenvolvimento Humano pela Universidade de São Paulo (2003). Professora Titular da Universidade Federal do Espírito Santo. Coordenadora do Laboratório de Psicologia da Moralidade (LAPSIM) da UFES. Pesquisadora Capixaba da Fundação de Amparo à Pesquisa e Inovação do Espírito Santo (FAPES), bolsa suspensa em março/2017. Bolsista da CAPES no Programa Estágio Sênior no Exterior em março/2017 (proc. no 88881.118916/2016-01) na University of California, Berkeley. Contato: heloisamoulin@gmail.com

Debates do NER, Porto Alegre, ANo i 8, N. 32, P. 233-258, JUl./DeZ. 20 I 7 
homogeneizada, a fim de identificar as variáveis que podem influenciar o processo de construção do conceito de Deus.

Palavras-chave: Conhecimento Social; Representação de Deus; Método Clínico.

Abstract: Representations about God are elaborated with the same purpose as are all representations about social knowledge (organizing, explaining and meaning what occurs in social environment). The objective was to investigate the representations of children and adolescents about God, through interviews based on the Piagetian clinical method, with subjects of 6,10 and 14 years old. Criteria for analysis of the answers were elaborated, based on the work of Delval and Muriá Vila (2008), in order to identify different levels of elaboration of this representation. The results do not present relevant differences between the ages about the level of God's representation. However, they collaborate with the discussions about the construction of such representations from the person that apprehends them and, actively, rework them. New research is needed with a larger number of participants and a more homogenized sample in order to identify the variables that can influence the process of building the concept of God

Keywords: Social Knowledge; Representation of God; Clinical Method. 


\section{INTRODUÇÃO}

Ao nascer, o homem não dispõe de seus instrumentos intelectuais completos, nem de representaçóes da realidade que o rodeia, portanto, precisa ir construindo ambos paralelamente, ao longo de seu desenvolvimento, a partir de um trabalho que é pessoal, mas possível apenas com ajuda dos outros. Há, assim, uma dialética entre o individual e o social que faz com que se desenvolvam mutualmente (Delval, 1989). A construção das representações da realidade, incluindo nela o próprio sujeito e os outros, é, de acordo com Delval (2007), o maior legado da espécie humana. De fato, Piaget (2005) defende que uma das principais capacidades que os seres humanos possuem é a de construir representaçóes da realidade que o cerca, uma vez que o conhecimento do ambiente é uma forma essencial de adaptação ao meio.

O termo representação é empregado por Piaget (2005) em dois sentidos. Em uma definição mais ampla, representação abarca toda a inteligência de esquemas mentais. De forma mais restrita, faz referência à modelos mentais (evocação simbólica de realidades ausentes). A posição construtivista, baseada na teoria piagetiana, estabelece que não é possível ao sujeito conhecer a realidade tal como é sem a representar. Portanto, as representaçóes criadas são frutos tanto do que é socialmente transmitido quanto do que é construído pelo próprio do sujeito (Osti; Silveira; Brenelli, 2013). Logo, segundo autores que se fundamentam na abordagem piagetiana (Delval, 1992, 1994, 2007; Enesco et al., 1995; Denegri, 1998), os sujeitos elaboram representaçóes, apoiados sobre as estruturas cognitivas de que dispóem, a partir da própria experiência sobre os objetos que busca conhecer e das informaçóes recebidas das pessoas com quem convive, dos meios de comunicação e das instituiçóes sociais como família, escola e religião, por exemplo.

Essa última, podendo ser considerada uma das mais importantes, é capaz inclusive de gerar costumes e determinar comportamentos. Delval (2013, p. 26) aponta que a religião "é um fenômeno social de considerável complexidade e que está presente de alguma maneira em todas as sociedades, mas 
que também atende a necessidades diferentes, a diversas funçóes". Pode, por exemplo, trazer conforto quando os homens sáo confrontados com eventos que fogem ao seu domínio e à sua capacidade de intervenção. Portanto, a religião exerce fascínio sobre o ser humano (Konings, 1997). Apesar deste não compreender completamente suas origens ou da ideia de Deus nela implicada, não consegue desvencilhar das curiosidades e questionamentos que ela provoca ou os quais procura responder.

Vergote (2001), defende que as pessoas que vivem nas sociedades formadas pela modernidade podem colocar-se fora da religiáo metodologicamente ou por convicção. Ou seja, nessas civilizaçóes, os homens têm o direito e a possibilidade cultural e social de crer ou de náo crer naquilo que é pregado pela religiáo dissociada em seu contexto. Assim, eles podem, numa atitude científica, colocar-se do lado de fora da religiáo e estudá-la objetivamente. Nas palavras do autor:

Estudam-se filologicamente os textos sagrados, historicamente as igrejas, sociológica e psicologicamente a religiáo. A ciência é sem Deus, neutra com relação à fé religiosa; ela observa e explica o que pode. Isso não é ateísmo filosófico, mas ateísmo metodológico (Vergote, 2001, p. 15).

Vergote (2001), ao discutir o assunto, sob a ótica da Psicologia, assume essa atitude metodológica e indaga se a religiáo é, de fato, necessária para o bom funcionamento psicológico do homem. Argumenta que ela é, por excelência, um fenômeno propriamente humano e, paradoxalmente, não é uma construção puramente racional. E, como a Psicologia se propóe a estudar cientificamente aquilo que não é nem a lógica nem o corpo, a religiáo e, portanto, a representaçáo de Deus se constituem objetos de seu interesse.

Assim, sendo o Brasil um país religioso, com $86,8 \%$ da populaçáo declarando-se cristã - entre católicos e protestantes, segundo dados do Censo de 2010 divulgados pelo Instituto Brasileiro de Geografia e Estatística (2010) -, pesquisadores têm buscado compreender, do ponto de vista psicológico, o alcance da religiáo nas diversas áreas da vida humana. Dentre os estudos 
realizados no país, estão aqueles que investigam a influência religiosa no processo de enfretamento de doenças (Cerqueira-Santos; Koller; Pereira, 2004; Faria; Seidl, 2005; Panzini; Bandeira, 2007; Gobatto; Araujo, 2010; Duarte; Wanderley, 2011; Paiva, 1998), na saúde mental (Peres; Simão; Nasello, 2007; Dalgalarrondo, 2006, 2007, 2008; Menezes Jr.; Alminhana; Moreira-Almeida, 2012), na sexualidade (Silva et al., 2008), no que tange à qualidade de vida (Panzini et al., 2011), na dependência química (Dalgalarrondo et al., 2004; Silva et al., 2010; Pillon et al., 2011) e na educação (Paiva, 2006). Também há trabalhos, no campo da Psicologia, sobre a experiência e o desenvolvimento religioso (Amatuzzi, 1998a, 1998b, 1999, 2000, 2001), a religiosidade nos grupos de ajuda/apoio (Roehe, 2004; Lagercrantz, 2007), a experiência religiosa na religião institucionalizada (Mendonça, 2004), entre outros.

Outra representação fortemente influenciada pela religião é a ideia de Deus. De fato, apesar de ser diferente entre hinduístas, islamitas, judeus e cristãos, a representação sobre Deus traz consigo características específicas, já que são construídas fora do alcance da experiência (Delval; Muriá Vila, 2008), ou seja, não é possível agir sobre o Ser divino, apenas sobre seu conceito. Assim, para construir uma representação sobre Deus, independentemente de qual Deus seja, é necessário que haja uma transmissão social. Seja por meio de um ensino religioso sistemático, dos meios de comunicação, das trocas interindividuais, ou de qualquer outra forma de difusão, as representaçóes sobre Deus sempre serão (re) construídas pelos sujeitos a partir de um elemento que é social.

Portanto, supóe-se que tais representaçóes, em alguma medida, podem fazer parte também do imaginário infantil. Delval e Muriá Vila (2008) assinalam que apesar de não serem produzidas espontaneamente em crianças pequenas, as ideias sobre Deus não são recebidas passivamente: são reelaboradas pelas crianças a partir das capacidades cognitivas de que dispóem. Além disso, Piaget (1970) afirma que as ideias vão sendo transformadas e sofisticadas na medida em que os sujeitos se desenvolvem, assim, pode-se inferir que o conhecimento sobre Deus é apreendido e representado de 
diferentes formas pelas crianças durante o processo de desenvolvimento. $\mathrm{Ou}$ seja, os sujeitos vão elaborando, ao longo desse processo, suas ideias sobre Deus, embasados nos instrumentos intelectuais de que dispóem e de forma compatível com o conjunto de crenças que compartilha (Delval, 1989).

Amatuzzi (2000, p. 17), ao ponderar sobre o desenvolvimento religioso, entendido como "o desenvolvimento pessoal no campo das indagaçóes por um sentido último (campo religioso)", estabeleceu como hipótese que os sujeitos passariam por nove etapas sucessivas, durante o seu percurso de vida. Para o autor, o desenvolvimento religioso se processa em paralelo com o desenvolvimento humano (tal qual proposto por Piaget) e, portanto, em cada etapa desse desenvolvimento, o sujeito encontra um desafio que precisa superar em direção ao sentido último. Baseando-se na teoria de Piaget (sobre o desenvolvimento cognitivo), nas pesquisas de Fowler (sobre os estágios da fé), na teoria de Kolberg (sobre o desenvolvimento moral) e em sua própria experiência como investigador do tema, Amatuzzi (2000) definiu essas etapas do desenvolvimento pessoal caracterizadas pelos seus desafios e experiências básicas.

Segundo Amatuzzi (2000), na 1. a etapa (0 a 1,5 anos), o desafio central é descobrir um mundo independente do eu e a experiência básica ligada à superação deste desafio é a confiança estabelecida na relaçáo com os pais. Essa confiança básica é o fundamento de todas as formas posteriores de fé ou religiáo. Na 2. ${ }^{a}$ etapa ( 2 a 6 anos), o desafio é abrir-se a uma relação onde o outro é aceito em sua separaçáo e autonomia. A experiência ligada à superação deste é a linguagem, enquanto reconstrução simbólica. A religião estará encontrando suas primeiras expressóes simbólicas concretas, a partir do que vai sendo recebido. Na 3. ${ }^{a}$ etapa ( 7 a 12 anos), O desafio é descobrir-se ativo e capaz. Sendo superado, desenvolve-se a auto segurança e a autoestima. A religiáo começa a se expressar agora através de histórias que condensam seu sentido. Na 4. a etapa (13 a 18/20 anos), o desafio é descobrir uma verdade pessoal mais profunda e a experiência ligada à superação deste relaciona-se à escolha pessoal. Nesse momento, a religiáo, como parte da identidade recebida, tende a ser questionada. Na 5.a etapa (18/20 a 30 anos), o desafio é 
abrir-se para uma relação mais pessoal e profunda, associada à experiência de intimidade. A sustentação de uma postura religiosa diante da vida passa a ser condicionada a uma experiência pessoal, mais crítica e refletida. $\mathrm{Na} 6{ }^{\mathrm{a}}$ etapa (30 a 35/40 anos) o desafio é gerar e cuidar. Se houver uma vivência religiosa autêntica, tende a se expandir criativamente no meio, em um sentimento de integração maior. Na 7. etapa (35/40 a 60 anos), o desafio é superar rotinas e padróes assumidos, relativizando normas e papéis sociais, o que pode levar a uma fé mais pessoal, superando aspectos rígidos e estereotipados, ou então a um abandono da religião até então professada. Na 8. etapa (60 a 80 anos), o desafio é aprofundar a libertação iniciada na etapa anterior. O sistema de orientação, religioso ou não, se relativiza. $\mathrm{O}$ conceito é vivido apenas como instrumento da experiência. $\mathrm{Na} 9{ }^{\mathrm{a}}$ etapa (depois dos 80 anos), a última proposta por Amatuzzi (2000) acerca do desenvolvimento religioso, o desafio é passar da vida individual para algo radicalmente diferente, e entregar-se em paz nessa passagem. A preparação para a entrega absoluta, ou ela própria, se constitui no supremo ato religioso (ou implicitamente religioso quando a referência ao transcendente não é conceituada).

Os autores já citados Delval e Muriá Vila (2008) investigaram, a partir de uma abordagem piagetiana, no México e em Madri, como crianças de 6 a 15 anos, estudantes de colégios católicos, representam Deus, as origens e a morte. Ao discutir especificamente o desenvolvimento da representação de Deus, Delval e Muriá Vila (2008) o fazem a partir de cinco aspectos dessa representação: a concepção de Deus, o lugar onde Deus vive, as coisas sobre as quais Deus intervém, o poder de Deus e a comunicação com Deus. Os autores propóem que o desenvolvimento dessa representação pode ser considerado em três níveis distintos: o 1. nível, "imagens fantásticas populares" (Delval; Muriá Vila, 2008, p. 27), vai até aproximadamente aos 10-11 anos, a concepção de Deus vincula-se estritamente com a ensinada pela religião; nesse nível, Deus é aquela imagem transmitida e adaptada à capacidade de compreensão dos sujeitos dessas idades, com traços humanos, semelhante às pessoas. O 2. ${ }^{\circ}$ nível, "Deus torna-se independente dos homens" (Delval; Muriá Vila, 2008, p. 38), a partir dos 10-11, aproximadamente, até os 13-14 
anos, as representaçôes caminham para uma espiritualização de Deus, ainda que sua imagem tenha traços materiais. Nesse nível, contudo, começa-se a duvidar destes traços e começa-se a ver Deus como algo mais imaterial. $\mathrm{O}$ 3. o nível, "um Deus abstrato e imaterial” (Delval; Muriá Vila, 2008, p. 48), a partir dos 13-14 anos, aproximadamente, Deus é concebido claramente como um ser imaterial. Deus passa a ser entendido como uma ideia interna, que tem a ver com a consciência dos indivíduos.

Uma pesquisadora que investigou a representação de Deus com crianças brasileiras, a partir de um enfoque piagetiano, foi Santos (2007). Em seu trabalho, a autora objetivou explorar como a concepçáo infantil sobre Deus evolui. Para tanto, solicitou a dez crianças de 7 e 11 anos que fizessem um desenho sobre Deus e utilizou um roteiro de entrevista semiestruturado para investigar a concepção de seus participantes. A partir da categorização das respostas, Santos (2007) observou que as crianças de 7 anos priorizaram, durante a entrevista, a moradia de Deus, suas funçóes, a concepção de um Deus punitivo e poderoso e também relacionaram Deus com a morte. Para as crianças de 11 anos, ressalta-se a ideia de Deus como criador, suas qualidades, a imagem de Deus como Pai e sua associação com a Bíblia. Em todas as categorias as crianças construíram a partir de ensinamentos religiosos de base cristã suas próprias concepçóes sobre a existência e a natureza de Deus. Santos (2007) assinala que a principal religião do ocidente (o cristianismo), sendo um desdobramento do judaísmo, é uma religião monoteísta que, entre seus ensinamentos, defende que Deus é um ser espiritual e pessoal, perfeito e santo. Também é concebido como o criador do universo, aquele que o conduz e governa. É um Ser constituído dos poderes de pensar, sentir, querer e, ainda mais, de consciência. $\mathrm{O}$ que, de certa forma, apareceu nos discursos de seus participantes.

O que fica claro nesses trabalhos (Amatuzzi, 2000; Santos, 2007; Delval; Muriá Vila, 2008) é que a ideia de Deus não é inata e não é estática, ela sofre alteraçóes na medida em que o indivíduo se desenvolve, amadurece, sendo influenciado com o que aprende em seu meio, e, nesse processo, aprende a dar significados, explicaçóes, diferentes para um mesmo fenômeno. $\mathrm{O}$ 
que se pode afirmar do ponto de vista psicogenético (Piaget, 1970, 2005) é que os sujeitos, no decurso do processo de desenvolvimento, têm seus instrumentos intelectuais alterados, modificados, lhes possibilitando pensar e construir representaçôes (incluindo aí as representaçóes sobre Deus), de formas distintas, durante todo o processo.

Outros trabalhos sobre o tema que podem ser citados são o de Núñez (2012), desenvolvido em Bogotá, acerca das ideias infantis sobre Deus; o de Tamminen (1994) sobre a experiência com Deus na perspectiva de crianças e adolescentes finlandeses e o estudo realizado por Dickie et al. (1997) sobre a relação entre o relacionamento com o pai e a concepção de Deus de crianças norte americanas com idades entre 4 e 11 anos. O que há de acordo, na maioria dos estudos, é que as ideias sobre Deus que aprendem e desenvolvem as crianças parecem ser influenciadas pela cultura, pelas experiências delas com os adultos que compartilham sobre a fé e também pelos símbolos e ensinamentos da religião dominante em seu círculo social.

Como as representaçôes sobre Deus são elaboradas com o mesmo objetivo que o são todas as representaçóes sobre as quais versa o conhecimento social (organizar, explicar e significar o que ocorre em seu meio), e tendo em vista que as representaçóes de que dispóem os sujeitos influenciam inclusive a forma como agem e interagem no mundo social, objetivou-se investigar a concepção sobre Deus, de crianças e adolescentes, analisando, assim, sua (re) elaboração em diferentes momentos do processo de desenvolvimento, e verificar, se houver, diferenças e semelhanças entre crianças de diferentes idades, em relação a tais concepçóes.

\section{METODOLOGIA}

\section{Participantes}

Participaram da pesquisa 6 sujeitos, selecionados por conveniência (portanto, não se definiu religião, classe social, escolaridade), igualmente divididos quanto sexo, sendo dois de 6 anos, dois de 10 anos e dois de 14 
anos. Definiram-se três faixas etárias distintas (6, 10 e 14 anos) pela possibilidade de compreender três momentos distintos no processo desenvolvimento.

Como as concepçóes sobre Deus são construídas a partir da religião na qual se está inserido (Delval; Muriá Vila, 2008), importante ressaltar que os participantes tinham contato com a religião institucionalizada (cristianismo), frequentavam assiduamente as missas (ou cultos) e programaçóes da igreja. De fato, se autodeclararam católicos ou protestantes e afirmaram que eram levados aos eventos religiosos pelos pais, amigos da família e/ou familiares.

\section{Instrumentos E Procedimentos}

Primeiramente foi feito um contato com os responsáveis pelos participantes explicando o objetivo da pesquisa e solicitando que, caso concordassem com a participação do (a) filho (a), assinassem o Termo de Consentimento Livre e Esclarecido para Participação em Pesquisa. Em seguida, foi acordado com cada um o melhor local para realização da mesma. Assim, foi realizada a entrevista individual sobre representação de Deus, baseada no método clínico. Tomando por base o trabalho de Delval e Muriá Vila (2008), foram elaboradas 15 questóes que visavam investigar quatro diferentes aspectos da representação de Deus (1. Como Deus é, 2. Habitação de Deus, 3. Relacionamento com Deus e 4. Função de Deus). A entrevista foi registrada com um gravador digital e, posteriormente, transcrita para análise.

\section{Resultados e Discussão}

Os dados obtidos na entrevista permitiram a elaboração de quadros de organização e avaliação. Tais quadros abrigam os critérios de análise organizados segundo a sequência de perguntas do roteiro, elaborado em função dos quatro aspectos investigados na representação de Deus, e a frequência de respostas encontradas em cada um deles. Cada aspecto possui quadro específico, com critérios específicos. Isso se fez necessário uma vez que cada um deles investiga características e conteúdos diferentes, o que implica em quantidades diferentes de perguntas e, consequentemente, de critérios esta- 
belecidos para a análise. Os critérios de análise e níveis utilizados na análise das respostas foram baseados na proposta de Delval e Muriá Vila (2008).

Os critérios permitem avaliar o processo de desenvolvimento da representação de Deus, tal qual proposto por Delval e Muriá Vila (2008), em três níveis evolutivos que serão discutidos ao apresentar os dados. Importante observar que os quadros apresentam a frequência de resposta em todos os níveis, contudo serão discutidos apenas aqueles nos quais foram encontradas respostas dos participantes.

Além dos quadros, alguns trechos de entrevistas serão apresentados durante as discussóes. Nestes, as falas dos entrevistados estarão em itálico para diferenciá-las das falas da pesquisadora. Esses trechos objetivam exemplificar as respostas consideradas em cada nível e ressaltar a qualidade do dado, a saber, a elaboração pessoal e íntima de cada sujeito acerca da própria concepção de Deus.

Dessa forma, os resultados serão apresentados separadamente em função dos quatro aspectos investigados na representação de Deus: 1 . Como é Deus, 2. Habitação de Deus, 3. Relacionamento com Deus e 4. Função de Deus.

As questóes que buscavam investigar o Aspecto 1, Como é Deus, referiam-se às características, qualidades e defeitos que os participantes atribuíam a Deus.

Os critérios de análise, então, foram delimitados para identificar os três Níveis de desenvolvimento da noção de Deus, no que concerne ao Aspecto 1. Assim, pode-se considerar uma resposta como Nível I quando: a. Descreve características antropomórficas, tal qual apresentadas em livros religiosos; b. Delimita o sexo masculino; ou c. Compreende Deus como uma pessoa, mas provida de perfeição e características excepcionais. A resposta é classificada no Nível II quando: d. Descreve características e referências a traços morais; e. Atribui ambos os sexos; ou f. Compreende Deus como uma pessoa, mas diferente dos humanos por sua natureza divina, embora também apresente defeitos. E, no Nível III, a resposta: g. Não descreve características antropomórficas; h. Não atribui sexo; ou i. Compreende 
Deus como uma ideia interna e pessoa. O Quadro 1 apresenta a frequência de respostas encontradas em cada nível.

Quadro 1 - Frequência das repostas sobre Como é Deus

\begin{tabular}{|c|c|c|c|}
\hline Níveis & $\mathbf{6}$ anos & $\mathbf{1 0}$ anos & $\mathbf{1 4}$ anos \\
\hline I & 4 & 3 & 4 \\
\hline II & 2 & 4 & 3 \\
\hline III & 0 & 1 & 0 \\
\hline
\end{tabular}

Fonte: Elaborado pelos autores.

Em relação ao Aspecto 1 da representação de Deus, a maioria das respostas dos participantes de 6 anos se concentra no Nível I; dos de 10 anos, nos níveis I e II, como também dos de 14 anos. Ao falar sobre as características de Deus, explicando como ele é, no Nível I os sujeitos descrevem Deus de forma mais material, com traços físicos humanos. Deus também é identificado como uma pessoa do sexo masculino, e isso se justifica tanto por seus traços masculinos (barba, bigode) quanto por seu nome ("se fosse mulher seria Deusa”, argumentou um participante). A seguir, os fragmentos das entrevistas exemplificam o que foi encontrado sobre essa questáo.

Para você como é Deus? Poderia me explicar? - Eu acho que ele tem o cabelo até aqui (mostra os ombros), ai tem barba em volta, tem o olho preto e o nariz dele é meio pontudo e a bochecha assim (coloca as mãos apertando as bochechas) $e$ a boca assim (sorri). Você acha que Deus é uma pessoa ou não? - Acho que é. Deus é homem, mulher, os dois ou nenhum dos dois? - Homem. Por quê? - Porque ele tem... bigode, tem... tem um monte de coisas de homem. (Gabriela, 6 anos)

Para você como é Deus? - Uma pessoa que não é como a gente. É diferente. Como assim? Poderia me explicar? - Não dá. Não dá para explicar Deus. Então você acha que Deus é uma pessoa ou não? - É. Deus é homem, mulher, os dois ou nenhum dos dois? - Homem. Por quê? - Porque o nome já diz: "Deus". Se fosse mulher seria "Deusa". (Roger, 14 anos) 
As falas desses participantes estão em acordo com o exposto por Amatuzzi (2000) ao ponderar que, nas primeiras fases do que denomina desenvolvimento religioso, os símbolos religiosos já fazem algum sentido para a criança, mas este sentido ainda é vivenciado pela criança como algo externo a ela, ainda estritamente ligado aos conteúdos concretos das histórias que lhe são contadas.

No Quadro 1 é possível observar que participantes de todas as idades emitiram respostas classificadas como Nível II. Isso implica dizer que tais respostas contém a descrição de traços físicos, mas também apresentam uma análise que os ultrapassa, de certa forma, mostrando Deus como algo mais imaterial. A fala a seguir pode exemplificar:

Para você como é Deus? - Deus é tudo na minha vida. Poderia me explicar como você acha que Deus é? Como você O imagina? - Imagino que Ele seja bom, que ajuda todas as pessoas que pedirem a Ele. Você acha que Deus é uma pessoa ou não? - Mais ou menos. Ele tem corpo de uma pessoa, mas não daqui. Ele é do céu, não daqui. Deus é homem, mulher, os dois ou nenhum dos dois? - Os dois. Por quê? - Porque Ele é como um pai e como uma mãe, um irmão e uma irmã. Como você precisar, Ele é. (Kaio, 10 anos)

Kaio (10 anos) afirma que Deus tem um corpo de uma pessoa, "mas não daqui", inferindo que é algo diferente. O que se comprova na ausência de traços antropomórficos ao descrever Deus, já apontando para uma característica de resposta de Nível III. Ou seja, respostas que explicam Deus de forma mais abstrata. Essa nuance de respostas de níveis diferentes emitidas pelo mesmo sujeito pode ser compreendida a partir dos trabalhos de Delval e Muriá Vila (2008) e Amatuzzi (2000) nos quais os autores discutem que, embora haja uma tendência em se prender a realidades externas, em determinado momento a relação estabelecida com a ideia de Deus não é de mera passividade: o sujeito passa a significar sua experiência, ou seja, Deus é uma "pessoa", mas também é entendido com traços de personalidade ("bom", "ajuda as pessoas") e o sujeito ainda lhe atribui significado pessoal ("Deus é tudo na minha vida"). 
Ao falar sobre as qualidades e defeitos de Deus, os seis participantes afirmam que Deus tem qualidades. A bondade de Deus foi citada por todos, outras qualidades mencionadas referiam-se ao fato de Deus ter poder, abençoar e ser "legal". Apenas um participante, Kaio, de 10 anos, afirmou que Deus também tem defeitos, uma vez que, mesmo podendo evitar, ele permite que algumas pessoas o abandonem.

As questōes que investigavam sobre o Aspecto 2, Habitaçáo de Deus, referiam-se ao local onde Deus vive e com quem vive. Os critérios de análise delimitados visavam identificar os três níveis de desenvolvimento da noção de Deus, no que concerne ao Aspecto 2. Nesse sentido, ao falar sobre a habitação de Deus, a resposta pode ser considerada como Nível I quando: a. Identifica o céu (ou outro lugar concebido como material) como local da habitaçáo de Deus; e/ou b. Afirma que Deus vive rodeado de personagens bíblicos e/ou familiares que já morreram. A resposta é classificada no Nível II quando: c. Indica que Deus está presente/vive de forma mais imaterial nas pessoas; e/ou d. Afirma que Deus vive sozinho. E, no Nível III, a resposta: e. Alega que, ao mesmo tempo em que náo vive em um lugar específico, Deus está em todos os lugares simultaneamente; e/ou f. Desconsidera a possibilidade de Deus viver só ou em companhia. O Quadro 2 destaca as respostas em cada nível.

Quadro 2 - Frequência das repostas sobre a Habitação de Deus

\begin{tabular}{|c|c|c|c|}
\hline Níveis & $\mathbf{6}$ anos & $\mathbf{1 0}$ anos & $\mathbf{1 4}$ anos \\
\hline I & 4 & 2 & 4 \\
\hline II & 0 & 2 & 0 \\
\hline III & 0 & 0 & 0 \\
\hline
\end{tabular}

Fonte: Elaborado pelos autores.

Em relação ao Aspecto 2 da representação de Deus, as respostas dos participantes de 6 e 14 anos se encontram no Nível I; dos de 10 anos, entre o Nível I e o Nível II. Sobre a Habitação de Deus, as respostas identificadas como Nível I referem-se a um lugar concreto, um espaço que pode ser 
delimitado, como o céu, por exemplo, como ensinado pela religião. Para a maioria dos participantes, Deus vive no Céu, e, sobre com quem vive são citados os anjos (em 4 respostas), Jesus (em 2 respostas), Maria (1 resposta) e familiares que já morreram (1 reposta).

Diferentemente dos dados aqui mencionados, em sua pesquisa sobre concepção de Deus, Santos (2007) constatou que a ideia de vincular Deus a um local preestabelecido (uma moradia) era mais comum em crianças menores.

No Nível II identificam-se as respostas que não delimitam um local específico, indicam que Deus está presente e/ou vive de forma mais imaterial nas pessoas. Embora ainda ligada à ideia de espaço, este, bem como o próprio Deus é concebido de forma mais imaterial e, sendo assim, Ele vive sozinho. A resposta de Helena pode exemplificar respostas classificadas como Nível II:

Você acha que Deus vive em algum lugar? - Não. Ele vive em lugar nenhum? - É... por aí... Me explica isso então. - Ele vive em qualquer casa, nas pessoas. Ele vive só ou com alguém? - Ele vive sozinho. (Helena, 10 anos)

As questóes que objetivavam compreender o que os participantes pensavam sobre o Relacionamento com Deus, referiam-se a possibilidade de se relacionar com Deus, ao tipo de relacionamento estabelecido, a possibilidade de se comunicar com Deus e a possibilidade de resposta divina. Os critérios de análise delimitados para identificar o Nível I do Aspecto 3, são: a. A comunicação não é possível ou possível apenas por meio da oração; b. A comunicação gira em torno das oraçóes aprendidas e os pedidos (coisas materiais concretas); c. Deus náo responde ou responde concedendo o que lhe foi pedido; e/ou d. O relacionamento com Deus é impessoal. A resposta é classificada no Nível II quando: e. A comunicação é possibilitada pela oração e pelo pensamento; f. A comunicação relaciona-se às oraçóes aprendidas e aos pedidos (coisas náo materiais); g. Deus responde por meio do pensamento, da alma ou coração; e/ou h. O relacionamento é visto como pessoal. Nas respostas de Nível III: i. A comunicação é indireta e relaciona- 
se mais a uma reflexão moral e/ou confissão; j. A "comunicação" implica encontrar ajuda para pensar sobre as próprias ações ou tomar decisões; $\mathrm{k}$. Deus responde indiretamente, como uma ajuda na tomada de decisóes; 1. O relacionamento implica um processo subjetivo de conversação consigo mesmo. O Quadro 3 apresenta a frequência de resposta em cada nível.

Quadro 3 - Frequência das repostas sobre o Relacionamento com Deus

\begin{tabular}{|c|c|c|c|}
\hline Níveis & $\mathbf{6}$ anos & $\mathbf{1 0}$ anos & $\mathbf{1 4}$ anos \\
\hline I & 6 & 5 & 6 \\
\hline II & 0 & 3 & 4 \\
\hline III & 0 & 1 & 0 \\
\hline
\end{tabular}

Fonte: Elaborado pelos autores.

Em relação ao Aspecto 3 da representação de Deus, a maioria das respostas dos participantes encontra-se no Nível I. Entretanto, os participantes de 6 anos apresentam respostas apenas de Nível I; os de 10 anos, de todos os níveis e os de 14 anos, apresentam respostas de Nível I e II. Sobre o Relacionamento com Deus, no Nível I estão as respostas que afirmam não acreditar na possibilidade de falar com Deus (por se tratar de um ser invisível), bem como aquelas que indicam a possibilidade de falar com Deus, através da reza ou oraçáo, mas náo acreditam que Deus responda, ou que Deus fale com as pessoas. Assim, o relacionamento com Deus (quando é apontada a possibilidade), é visto como impessoal, Deus é um ser distante, como ilustram os trechos a seguir:

Você acha que é possível falar com Deus? - Não. Por que não? - Porque Ele é invisivel. Você fala com Ele? - Não... E você acha que é possível ter um relacionamento com Deus? - Não. Ele mora longe, ele só fica no céu. (Igor, 6 anos)

Você acha que é possível falar com Deus? - Sim. Você fala com ele? - Sim. Como? - Orando, eu peço a ele as coisas que preciso. E você acha que Deus te responde? - Sim. Ele faz o que eu peço. (Helena, 10 anos) 
A explicação de Helena (10 anos) está em acordo com o que Oser e Gmünder (1991 apud Amatuzzi, 2000) observaram em seu estudo sobre os estágios do julgamento religioso: em determinado momento no curso do desenvolvimento, os sujeitos acreditam que é possível influenciar Deus por meio das preces, orações, obediência às regras e etc. A prova dessa "influência", ou dessa interação com o divino, seria a resposta de Deus às oraçóes, o que se evidencia, na fala de Helena (10 anos), ao afirmar que Deus faz aquilo que ela pede.

No Nível II encontram-se as respostas que sinalizam a possibilidade de falar com Deus, por meio das oraçóes e do pensamento, bem como a possibilidade de resposta, sendo esta compreendida por meio do pensamento, da alma ou do coração. O relacionamento com Deus começa a ser visto, assim, como algo mais pessoal. Para os participantes (com exceção do Igor, de 6 anos) existe a possibilidade de se relacionar com Deus. Alguns disseram que é possível se relacionar com Deus como Pai (Kaio, de 10 anos, e Eliza, de 14 anos), os outros não identificaram um tipo específico de relacionamento, mas afirmaram que, com Deus, o relacionamento é melhor do que o relacionamento com as pessoas (Helena, de 10 anos) e que só com sinceridade é possível estabelecer esse relacionamento (Roger, de 14 anos). O trecho a seguir exemplifica as respostas encontradas nesse nível:

Você acha que é possível se relacionar com Deus? - Sim, porque Deus é como um pai. Ele cuida da gente, nos protege. E você acha que é possível falar com Deus? - Sim. Orando... E também no pensamento, assim, falando no seu pensamento o que está no seu coração. Você fala com Ele? - Falo... eu peço perdão pelos meus pecados, peço para cuidar da minha família, me abençoar, assim. E ele te responde? - Sim, mas não é algo que eu ouço, é algo que eu sinto. Eu não ouço a resposta, eu a sinto... (Eliza, 14 anos)

Entre os participantes, apenas Kaio (10 anos) apresentou resposta considerada de Nível III, por refletir, na oração, sobre o que deve fazer, sobre "o que é certo". 
Ele te responde? - Sim... mas não é assim. Não éouvindo, eu sinto. Como? - Eu pergunto: Deus, você quer que eu faça isso? Eu devo fazer aquilo? Eu penso sobre o que devo fazer, então sinto a vontade dele. Eu não ouço o que Ele diz, mas sinto no meu coração o que é certo. (Kaio, 10 anos)

Esse dado assinala certa disparidade em relaçáo aos dados encontrados por Delval e Muriá Vila (2008), uma vez que esse tipo de resposta foi encontrado apenas entre participantes mais velhos (14 anos). Isso porque as respostas apontam para uma abstração maior, já que a comunicação é indireta e relaciona-se mais a uma reflexão moral e o relacionamento implica em um processo subjetivo de conversaçáo consigo mesmo.

As questôes que buscavam investigar o Aspecto 4, Função de Deus versavam sobre o que Deus faz, se interfere na vida das pessoas, como interfere e apresentava um exemplo específico para que os participantes analisassem se e como, naquela situação, Deus interferiria.

Os critérios de análise, então, foram delimitados para identificar os três Níveis de desenvolvimento da noção de Deus, no que concerne ao Aspecto 4. Assim, pode-se considerar uma resposta como Nível I quando: a. Infere que Deus participa/interfere diretamente e concretamente em cada uma das coisas que acontecem no mundo; e/ou b. Atribui a Deus a responsabilidade de evitar que as pessoas se machuquem. A resposta é classificada no Nível II quando: c. Infere que Deus participa fundamentalmente nas coisas boas e age por meio dos sentimentos e pensamentos; e/ou d. Atribui a Deus a responsabilidade de manter as coisas em ordem. E, no Nível III, a resposta: e. Infere que Deus está consciente de tudo o que acontece, mas não intervém; e/ou f. Atribui a Deus a responsabilidade de criar as coisas para então funcionarem por si mesmas. O Quadro 4 apresenta a frequência de respostas em cada nível. 
Quadro 4 - Frequência das respostas sobre a Função de Deus

\begin{tabular}{|c|c|c|c|}
\hline Níveis & $\mathbf{6}$ anos & $\mathbf{1 0}$ anos & $\mathbf{1 4}$ anos \\
\hline I & 3 & 1 & 1 \\
\hline II & 1 & 2 & 2 \\
\hline III & 0 & 0 & 0 \\
\hline
\end{tabular}

Fonte: Elaborado pelos autores.

Em relação ao Aspecto 4 da representação de Deus, a maioria das respostas dos participantes de 6 anos se concentra no Nível I. Sobre a Função de Deus, o Nível I é caracterizado por respostas que atribui a Deus a função de evitar que as pessoas se machuquem ou se sintam infelizes. Além disso, inferem a Deus participação e interferência divina diretamente e concretamente em cada uma das coisas que acontecem no mundo. A interferência divina é vista de forma material, como se o próprio Deus se materializasse para intervir, como pode ser observado na fala da participante:

Para você, qual é a função de Deus, o que ele faz? - Ele ajuda as pessoas. Se a pessoa pediu uma coisa, e a pessoa rezar, ele faz. E eu acho que ele é o homem mais bonzinho do mundo. Você acha que Deus interfere ou não na vida das pessoas? - Eu acho que quando dois estâo brigando, Deus interfere e fala assim: "para! por favor...". Como Deus fala com eles? - Ele chega e fala: "para!". E por que Deus faz isso? - Para os meninos náo se machucarem. (Gabriela, 6 anos)

Sobre o que Deus faz, ou qual seria a função de Deus, os participantes falaram sobre "ajudar as pessoas" (4 respostas), "abençoar" (2 respostas), "salvar" (2 respostas), atender a pedidos/oraçôes (2 repostas), "ficar no céu" (1 resposta).

Em relação a esse aspecto, a maioria das respostas dos participantes de 10 e 14 anos, encontra-se no Nível II. Para estes, alguns conflitos como entre a bondade de Deus e a maldade percebida no mundo, ficam claros. Contudo, o conflito é resolvido de forma simples, como pontuam Delval e Muriá Vila (2008), ao indicar que Deus interfere apenas nas coisas boas. 
Além disso, Deus age por meio de pessoas que aconselham, bem como dos próprios sentimentos e pensamentos.

Você acha que Deus interfere ou não na vida das pessoas? - Sim. De que forma? - Se alguém está fazendo alguma coisa errada, ele coloca uma pessoa ali para dizer que aquilo está errado. (Roger, 14 anos)

Imagine que duas crianças estão brigando, uma é mais forte e está batendo muito na outra. Você acha que Deus interfere nessa situaçáo? - Sim. De que forma? - Ele pode fazer assim... Dar um jeito na mente dele. Ai o outro pensa, ai depois Deus conversa e volta ao normal. (Helena, 10 anos)

Assim, ao inferir que pessoas veiculam a vontade de Deus, de alguma forma Roger (14 anos) percebe as pessoas como parte do mundo religioso. Deus, dessa feita, não está limitado apenas às histórias contadas pela religiấo, mas ele "fala", "age" no sujeito, como aponta Helena (10 anos), e por intermédio do sujeito, como aponta Roger (14 anos). O que também foi constatado por Oser e Gmünder (1991 apud Amatuzzi, 2000).

\section{CONSIDERAÇÕES FINAIS}

As ideias sobre Deus, advindas dos diversos segmentos da sociedade na qual a criança está inserida, são assimiladas por ela de diferentes formas ao longo do processo de desenvolvimento, conforme apontado por Santos (2007), Delval e Muriá Vila (2008), Amatuzzi (2010), entre outros. Essa pesquisa, portanto, colabora para a discussão da construção de tais ideias a partir do sujeito que as apreende e, de forma ativa, as reelabora. Também confirma as contribuiçóes do método clínico na investigação do conceito de Deus e evidencia a possibilidade de utilização dos critérios baseados no trabalho de Delval e Muriá Vila (2008) para análise desse conceito.

Nos resultados obtidos, diferente do esperado, considerando a pesquisa de Delval e Muriá Vila (2008), não foram constatadas semelhanças e diferenças relevantes entre as idades, aparecendo, entretanto, uma diferença qualitativa nas respostas de Kaio (10 anos) por serem mais elaboradas, 
inclusive, que as dos participantes mais velhos. Essa disparidade, contudo, aponta para certa limitação do estudo, que, selecionando os participantes por conveniência, acabou por impossibilitar a identificação e discussão das possíveis influências nesse resultado.

Portanto, novas pesquisas se fazem necessárias, com um número maior de participantes e uma amostra mais homogeneizada, a fim de identificar outras variáveis que podem influenciar o processo de construção do conceito de Deus, bem como outros conceitos (como justiça, honra e generosidade) que podem ser influenciados por ele.

\section{REFERÊNCIAS}

AMATUZZI, Mauro Martins. Experiência religiosa: busca de uma definição. Estudos de psicologia, Campinas, v. 15, n. 1, p. 49-65, 1998a.

. A experiência religiosa: estudando depoimentos. Estudos de psicologia, Campinas, v. 15, n. 2, p. 3-27, 1998 b.

. Religião e sentido de vida: um estudo teórico. Temas em Psicologia, Ribeirão Preto, v. 7, n. 2, p. 183-190, 1999.

. O desenvolvimento religioso: uma hipótese psicológica. Estudos de psicologia, Campinas, v. 17, n. 1, p. 15-30, 2000. Disponível em: <http://www.scielo.br/pdf/estpsi/v17n1/02.pdf>. Acesso em: 9 ago. 2014.

. Esboço de teoria do desenvolvimento religioso. In: PAIVA, Geraldo José de (Org.). Entre necessidade e desejo: diálogos da psicologia com a religião. São Paulo: Ediçôes Loyola, 2001. p. 25-52.

CERQUEIRA-SANTOS, Elder; KOLLER, Sílvia Helena; PEREIRA, Maria Teresa Lisboa Nobre. Religião, saúde e cura: um estudo entre neopentecostais. Psicologia: Ciência e Profissão, Brasília, DF, v. 24, n. 3, p. 82-91, 2004. Disponível em: <http://www.scielo.br/scielo.php?script=sci_arttext \&pid=S1414-98932004000300011\&lng=pt\&tlng=pt.10.1590/S141498932004000300011>. Acesso em: 4 ago. 2014. 
DALGALARRONDO, Paulo. Relações entre duas dimensões fundamentais da vida: saúde mental e religião. Revista Brasileira de Psiquiatria, São Paulo, v. 28, n. 3, p. 177-178, set. 2006. Disponível em: <http://www.scielo.br/scielo. php?script=sci_arttext $\&$ pid=S1516-44462006000300006\&lng=pt\&tlng=pt. \%2010.1590/S1516-44462006000300006>. Acesso em: 4 ago. 2014.

. Estudos sobre religião e saúde mental realizados no Brasil: histórico e perspectivas atuais. Revista de Psiquiatria Clínica, São Paulo, v. 34, supl. 1, p. 25-33, 2007. Disponível em: <http://www.scielo.br/scielo.php?script= sci_arttext\&pid=S0101-60832007000700005\&lng=pt\&tlng=pt. 10.1590/ S0101-60832007000700005>. Acesso em: 4 ago. 2014.

Religiáo, psicopatologia e saúde mental. Porto Alegre: Artmed, 2008.

DALGALARRONDO, Paulo et al. Religiáo e uso de drogas por adolescentes. Revista Brasileira de Psiquiatria, São Paulo, v. 26, n. 2, p. 82-90, 2004. Disponível em: <http://www.scielo.br/scielo.php?script=sci_arttext \&pid=S1516-44462004000200004\&lng=pt\&tlng=pt. 10.1590/S151644462004000200004>. Acesso em: 4 ago. 2014.

DELVAL, Juan. La representación infantil del mundo social. In: TURIEL, Elliot; ENESCO, Ileana; LINAZA, Josetxu (Org.). El mundo social en la mente infantil. Madrid: Alianza, 1989. p. 245-328.

El constructivismo y la adquisición del conocimiento social. Apuntes de Psicología, Sevilla, n. 36, p. 5-24, 1992.

. El desarrollo humano. Madrid: Siglo XXI, 1994.

Aspectos de la construcción del conocimiento sobre la sociedad. Educar em revista, Curitiba, v. 23, n. 30, p. 45-64, 2007. Disponível em: <http://www.scielo.br/pdf/er/n30/a04n30.pdf>. Acesso em: 28 maio 2014.

. O desenvolvimento psicológico humano. São Paulo: Vozes, 2013.

DELVAL, Juan; MURIÁ VILA, Irene. Los niños y Dios: ideas infantiles sobre la divindade, los orígenes y la muerte. Ciudad de México: Siglo XXI, 2008. 
DENEGRI, Marianella. La construcción de nociones económicas en la infancia y adolescencia. In: BAYONA, Jesús Ferro; AMAR, José Juan; LLANOS, Raimundo Abello (Ed.). Desarrollo humano: perspectivas siglo XXI. Barranquilla: Ediciones Uninorte, 1998.

DICKIE, Jane R. et al. Parent-child relationships and children's images of God. Journal for the Scientific Study of Religion, v. 36, n.1, p. 25-43, mar. 1997.

DUARTE, Flávia Meneses; WANDERLEY, Kátia da Silva. Religião e espiritualidade de idosos internados em uma enfermaria geriátrica. Psicologia: teoria e pesquisa, Brasília, DF, v. 27, n. 1, p. 49-53, jan./mar. 2011.

ENESCO, Ileana et al. La comprensión de la organización social en niños y adolescentes. Madrid: Cide, 1995.

FARIA, Juliana Bernardes de; SEIDL, Eliane Maria Fleury. Religiosidade e enfrentamento em contextos de saúde e doença: revisão da literatura. Psicologia: reflexão e crítica, Porto Alegre, v. 18, n. 3, p. 381-389, 2005.

GOBATTO, Caroline Amado; ARAUJO, Tereza Cristina Cavalcanti Ferreira de. Coping religioso-espiritual: reflexóes e perspectivas para a atuação do psicólogo em oncologia. Revista da SBPH, Rio de Janeiro, v. 13, n. 1, p. 52-63, jun. 2010.

INSTITUTO BRASILEIRO DE GEOGRAFIA E ESTATÍSTICA (IBGE). Censo demográfico 2010: características gerais da população, religião e pessoas com deficiência. Rio de Janeiro: IBGE, 2010.

KONINGS, Johan M. H.; ZILLES, Urbano (Org.). Religião e cristianismo. Porto Alegre: EDIPUCRS, 1997.

LAGERCRANTZ, Luciana Neves. A experiência religiosa no grupo dos alcoólicos anônimos. 2007. 76 f. Monografia (Graduação em Psicologia) - Centro Universitário de Brasília, Brasília, DF, 2007. 
MENDONÇA, Antônio Gouvêa. A experiência religiosa e a institucionalização da religião. Estudos Avançados, São Paulo, v. 18, n. 52, p. 29-46, 2004. Disponível em: <http://www.scielo.br/scielo.php?script=sci_arttext \&pid=S0103-40142004000300004\&lng=en \& $\ln$ g=es. 10.1590/S0103$40142004000300004>$. Acesso em: 9 ago. 2014.

MENEZES JR., Adair; ALMINHANA, Letícia; MOREIRA-ALMEIDA, Alexander. Perfil sociodemográfico e de experiências anômalas em indivíduos com vivências psicóticas e dissociativas em grupos religiosos. Revista de Psiquiatria Clínica, São Paulo, v. 39, n. 6, p. 203-207, 2012. Disponível em: <http://www.scielo.br/scielo.php?script=sci_arttext\& pid=S0101-60832012000600005\&lng=pt\&tlng=pt.10.1590/S010160832012000600005>. Acesso em: 4 ago. 2014.

NÚNEZZ, César Fernando Franco. La experiencia de Dios en la infancia. Reflexiones Teológicas, n. 9, p. 57-72, enero/jul. 2012. Disponível em: $<$ http://dialnet.unirioja.es/ servlet/articulo?codigo $=4087616>$. Acesso em: 4 ago. 2014.

OSTI, Andréia; SILVEIRA, Cristina Andrade Ferreira; BRENELLI, Rosely Palermo. Representaçóes sociais: aproximando Piaget e Moscovici. Schème: Revista Eletrônica de Psicologia e Epistemologia Genéticas, v. 5, n. 1, p. 35-60, 2013. Disponível em: <http://www2.marilia.unesp.br/ revistas/index. php/scheme/ article/view/3176>. Acesso em: 4 ago. 2014.

PAIVA, Geraldo José de. O Estado e a educaçáo religiosa: observaçóes a partir da psicologia. Psicologia: Teoria e Pesquisa, Brasília, DF, v. 22, n. 1, p. 63-67, jan./abr. 2006. Disponível em: <http://www.scielo.br/scielo.php? script=sci_arttext\&pid=S0102-37722006000100008\&lng=pt\&tlng=pt. 10.1590/S0102-37722006000100008>. Acesso em: 4 ago. 2014.

. AIDS, psicologia e religião: o estado da questão na literatura psicológica. Psicologia: Teoria e Pesquisa, Brasília, DF, v. 14, n. 1, p. 27-34, 1998. 
PANZINI, Raquel Gehrke; BANDEIRA, Denise Ruschel. Coping (enfrentamento) religioso/espiritual. Revista de Psiquiatria Clínica, São Paulo, v. 34, supl. 1, p. 126-135, 2007. Disponível em: <http://www.scielo.br/scielo. php?script=sci_arttext\&pid=S0101-60832007000700016\&lng=pt\&tlng=pt. 10.1590/S0101-60832007000700016>. Acesso em: 4 ago. 2014.

PANZINI, Raquel Gehrke et al. Validação brasileira do Instrumento de Qualidade de Vida/espiritualidade, religião e crenças pessoais. Revista de Saúde Pública, São Paulo, v. 45, n. 1, p. 153-165, 2011. Disponível em: <http://www.scielo.br/scielo.php?script=sci_arttext\&pid= S0034-89102011000100018\&lng=pt\&tlng=pt.\%2010.1590/S003489102011000100018>. Acesso em: 4 ago. 2014.

PERES, Julio Fernando Pietro; SIMÃO, Manoel José Pereira; NASELLO, Antonia Gladys. Espiritualidade, religiosidade e psicoterapia. Revista de Psiquiatria Clínica, São Paulo, v. 34, supl. 1, p. 136-145, 2007. Disponível em: <http://www.scielo.br/scielo.php?script=sci_arttext\&pid= S0101-60832007000700017\&lng=pt\&tlng=pt. $10.1590 / S 0101$ 60832007000700017>. Acesso em: 4 ago. 2014.

. A construção do real na criança. Rio de Janeiro: Zahar, 1970.

PIAGET, Jean. A representação do mundo na criança. São Paulo: Idéias \& Letras, 2005.

PILLON, Sandra Cristina et al. Uso de álcool e espiritualidade entre estudantes de enfermagem. Revista da Escola de Enfermagem da USP, São Paulo, v. 45, n. 1, p. 100-107, mar. 2011. Disponível em: <http://www.scielo.br/ scielo.php?script=sci_arttext\&pid=S0080-62342011000100014\&lng=pt\& tlng=pt.\%2010.1590/S0080-62342011000100014>. Acesso em: 4 ago. 2014. 
ROEHE, Marcelo Vial. Experiência religiosa em grupos de auto-ajuda: o exemplo de neuróticos anônimos. Psicologia em Estudo, Maringá, v. 9, n. 3, p. 399-407, set./dez. 2004. Disponível em: <http://www.scielo.br/ scielo.php?script $=$ sci_arttext $\&$ pid $=\$ 1413-73722004000300008 \& \operatorname{lng}=e n \&$ tlng=pt.\%2010.1590/S1413-73722004000300008>. Acesso em: 9 ago. 2014.

SANTOS, Elaine Franciny. A noção de Deus em crianças. 2007. 51 f. Monografia (Graduação em Psicologia) - Centro Universitário do Leste de Minas Gerais, Ipatinga, 2007.

SILVA, Cristiane Gonçalves da et al. Religiosidade, juventude e sexualidade: entre a autonomia e a rigidez. Psicologia em Estudo, Maringá, v. 13, n. 4, p. 683-692, out./dez. 2008. Disponível em: <http://www.scielo.br/ scielo.php?script=sci_arttext\&pid=S1413-73722008000400006\&lng=pt\& tlng=pt.\%2010.1590/S1413-73722008000400006 >. Acesso em: 4 ago. 2014.

SILVA, Cristiane Schumann et al. Relação entre prática religiosa, uso de álcool e transtornos psiquiátricos em gestantes. Revista de Psiquiatria Clínica, São Paulo, v. 37, n. 4, p. 152-156, 2010. Disponível em: <http://www.scielo.br/ scielo.php?script=sci_arttext\&pid=S0101-60832010000400002\&lng=pt\& tlng=pt.\%2010.1590/S0101-60832010000400002>. Acesso em: 4 ago. 2014.

TAMMINEN, Kalevi. Religious experiences in childhood and adolescence: a viewpoint of religious development between the ages of 7 and 20. The International Journal for the Psychology of Religion, v. 4, n. 2, p. 61-85, 1994. VERGOTE, Antoine. Necessidade e desejo da religião na ótica da psicologia. In: PAIVA, Geraldo José de (Org.). Entre necessidade e desejo: diálogos da psicologia com a religiáo. São Paulo: Ediçóes Loyola, 2001. p. 9-24.

Recebido em: 18/11/2016

Aprovado em: 03/07/2017 